Irawati:Pengaruh Green Marketing dan Green Product terhadap Keputusan Pembelian...

\title{
PENGARUH GREEN MARKETING DAN GREEN PRODUCT TERHADAP KEPUTUSAN PEMBELIAN PUPUK ORGANIK DI KIOS TANI MULYO KEDUNGREJO KABUPATEN LUMAJANG
}

\author{
Reni Selvi Irawati ${ }^{1}$ Nawangsih ${ }^{2)}$ \\ Program Studi Manajemen, STIE Widya Gama Lumajang, 67352, Indonesia \\ 1)Email: Renyselvy93@gmail.com \\ 2)Email: lovinawang@gmail.com
}

\begin{abstract}
This study aims to determine the effect of green marketing and green product depend on the decision to purchase organic fertilizer in Kios Tan Mulyo Kedungrejo Lumajang regency either partially or simultaneously. The research method used is multiple linear regression method by using hypothesis test that is $t$ test and $F$ test. The result of research indicate that partially for green marketing variable has no influence to purchase decision of organic fertilizer. Variable of green product there is significant influence to decision of purchasing organic fertilizer. While simultaneously there is the influence of green marketing and green product on purchasing decisions of organic fertilizer with a coefficient of determination ( $R$ square) of 0.406 was showed that $40.6 \%$ of organic fertilizer purchasing decisions can be explained by green marketing and green product, while the remaining 59,4\% influenced by other variables not research in this study.
\end{abstract}

\section{Keywords: Green Marketing, Green Product, Purchase Decision}

\begin{abstract}
Abstrak: Penelitian ini bertujuan untuk mengetahui pengaruh green marketing dan green product terhadap keputusan pembelian pupuk organik di Kios Tani Mulyo Kedungrejo Kabupaten Lumajang baik secara parsial maupun secara simultan. Metode penelitian yang digunakan adalah metode regresi linier berganda dengan menggunakan uji hipotesis yaitu uji t dan uji F. Hasil penelitian menunjukkan bahwa secara parsial untuk variabel green marketing tidak mempunyai pengaruh terhadap keputusan pembelian pupuk organik. Variabel green product terdapat pengaruh signifikan terhadap keputusan pembelian pupuk organik. Sedangkan secara simultan terdapat pengaruh green marketing dan green product terhadap keputusan pembelian pupuk organik dengan koefisien determinasi ( $R$ square) diperoleh sebesar 0,406 yang menunjukkan bahwa 40,6\% keputusan pembelian pupuk organik dapat dijelaskan oleh green marketing dan green product, sedangkan sisanya $59,4 \%$ dipengaruhi oleh variabel-variabel lain yang tidak diteliti dalam penelitian ini.
\end{abstract}

Kata Kunci: Green Marketing, Green Product , Keputusan Pembelian

Jurnal Ilmu Manajemen Advantage, Vol.01, No.1, Juni, 2017 
Irawati:Pengaruh Green Marketing dan Green Product terhadap Keputusan Pembelian...

\section{PENDAHULUAN}

Pemanasan global (global warming) yang semakin meningkat saat ini menjadi berdampak buruk bagi lingkungan, antara lain: kebakaran hutan, meningkatnya suhu bumi, permukaan air laut yang semakin tinggi dan menipisnya lapisan ozon. Kerusakan alam yang semakin parah mendorong kepedulian masyarakat untuk lebih peduli terhadap lingkungannya. Kebijakan pemerintah Kabupaten Lumajang menempatkan sektor pertanian sebagai salah satu sasaran pembangunan, menuju swasembada pangan.

Penggunaan pupuk organik dalam jangka panjang dapat meningkatkan produktifitas lahan dan mencegah degradasi lahan. Sumber bahan untuk pupuk organik sangat beranekaragam, karakteristik fisik dan kandungan kimia sangat beragam sehingga pengaruh dari penggunaan pupuk organik terhadap lahan dan tanaman dapat bervariasi. Pupuk organik yang ditambahkan ke dalam tanah akan mengalami beberapa kali fase perombakan oleh mikro organisme tanah untuk menjadi humus. Pemasaran hijau (green marketing) pada intinya menggambarkan pemasaran suatu produk yang didasarkan pada kinerja lingkungan. Pemasaran hijau tumbuh dan berkembang dalam beberapa tahap. Lee (2008) dalam Setiyaningrum \& Udaya dkk, (2015:309) menyatakan bahwa"pemasaran hijau dimulai pada dekade akhir tahun 1980-an ketika konsep pemasaran hijau pertama kali diperkenalkan". Kepedulian manusia mengenai kualitas lingkungan secara global mendorong perkembangan pemasaran hijau.

Selain green marketing, produk hijau (green product) mengalami perkembangan pesat dan memperoleh kepercayaan dari konsumen, seiiring penerapan teknologi yang makin canggih, penguatan pernyataan yang lebih tegas pada klaim iklan, regulasi dan insentif pemerintah serta pemeriksaan lebih dekat dari organisasi lingkungan media. Cooper (2000) dalam Sumarwan dkk, (2012:235) produk hijau atau yang sering disebut sebagai produk yang akrab lingkungan (environmental friendly product) cukup kompleks untuk didefinisikan.

Konsumen sekarang cenderung berhati-hati atau menjadi kritis terhadap lingkungan sekitar, pada saat melakukan keputusan pembelian konsumen biasanya melakukan banyak pertimbangan sebelum membeli produk yang ramah lingkungan. Setiadi (2003) dalam Mamang \& Sopiah (2013:121) mendefinisikan "inti dari pengambilan keputusan konsumen adalah proses pengintegrasian yang mengkombinasikan pengetahuan untuk mengevaluasi dua perilaku alternatif atau lebih". Perbedaan penelitian sekarang dengan peneliti terdahulu adalah tempat penelitian dan priode penelitian. Tempat yang digunakan dalam melakukan penelitian adalah Kios Tani Mulyo Kedungrejo Kabupaten Lumajang. Peneliti tertarik di bidang 
Irawati:Pengaruh Green Marketing dan Green Product terhadap Keputusan Pembelian...

manajemen pemasaran, khususnya tentang pengaruh green marketing dan green product terhadap keputusan pembelian, karena peneliti tertarik untuk mengetahui kesadaran masyarakat akan pentingnya pola hidup sehat yang semakin tinggi dan dapat membuka peluang petani khususnya dibidang pertanian agar petani menggunakan pupuk organik yang ramah lingkungan. Hadisuwito (2012:14), "pupuk organik adalah pupuk yang terbuat dari bahan organik atau mahluk hidup yang telah mati". Bahan organik ini akan mengalami pembusukan oleh mikro organisme sehingga sifat fisiknya akan berbeda dari semula. Pupuk organik termasuk pupuk majemuk lengkap, karena kandungan unsur haranya lebih dari satu unsur dan mengandung unsur mikro.

Kebutuhan pupuk yang semakin meningkat banyak petani di Kedungrejo yang mengeluh kekurangan pupuk untuk kebutuhan pertanian dan mencari pupuk ke desa tetangga, sehinggan Pak Puji berinisiatif membuka kios untuk membantu petani agar tidak kesulitan mencari pupuk. Awal pendirian Kios Tani Mulyo pada tahun 2000, dikarenakan kebutuhan kelompok tani banyak yang kesulitan mencari distributor untuk para petani, ketika itu didirikan secara individu dengan modal awal pinjam ke bank dan tempat pendirian usaha awalnya pinjam kios dengan sistim bagi hasil selama 3 tahun. Pada awal tahun 2003, Kios Tani Mulyo mulai memiliki tempat usaha sendiri. Kios Tani Mulyo Kedungrejo kabupaten Lumajang sementara ini hanya menjual pupuk dan benih hingga sekarang dan selanjutnya mempunyai program untuk menjual kebutuhan para petani.

Adapun permasalahan dapat dirumuskan sebagai berikut, 1) apakah terdapat pengaruh green marketing secara signifikan terhadap keputusan pembelian pupuk organik di Kios Tani Mulyo Kedungrejo Kabupaten Lumajang?, 2) apakah terdapat pengaruh green product secara signifikan terhadap keputusan pembelian pupuk organik di Kios Tani Mulyo Kedungrejo Kabupaten Lumajang?, 3) apakah terdapat pengaruh green marketing dan green product secara simultan signifikan terhadap keputusan pembelian pupuk organik di Kios Tani Mulyo Kedungrejo Kabupaten Lumajang?. Adapun tujuan penelitian ini adalah 1) untuk mengetahui pengaruh green marketing secara signifikan terhadap keputusan pembelian pupuk organik di Kios Tani Mulyo Kedungrejo Kabupaten Lumajang, 2) untuk mengetahui green product secara signifikan terhadap keputusan pembelian pupuk organik di Kios Tani Mulyo Kedungrejo Kabupaten Lumajang, dan 3) untuk mengetahui green marketing dan green product secara simultan signifikan terhadap keputusan pembelian pupuk organik di Kios Tani Mulyo Kedungrejo Kabupaten Lumajang. 
Irawati:Pengaruh Green Marketing dan Green Product terhadap Keputusan Pembelian...

\section{KAJIAN TEORI}

Manajemen. Menurut Sikula dalam Hasibuan (2015:3) "manajemen adalah aktivitas-aktivitas perencanaan, pengorganisasian, pengendalian, penempatan, pengarahan, pemotivasian, komunikasi, dan pengambilan keputusan yang dilakukan oleh setiap organisasi dengan tujuan untuk mengkoordinasikan berbagai sumber yang dimiliki oleh perusahaan sehingga akan dihasilkan suatu produk atau jasa secara efisien".

Manajemen Pemasaran. Menurut Kotler \& Keller (2009:5) "manajemen pemasaran (marketing management) sebagai seni dan ilmu memilih pasar sasaran dan meraih, mempertahankan, serta menumbuhkan pelanggan dengan menciptakan, menghantarkan, dan mengkomunikasikan nilai pelanggan yang unggul”.

Marketing Mix. Hair \& Daniel (dalam Rangkuti, 2009:21) menjelaskan bahwa bauran pemasaran adalah strategi produk, promosi, dan penentuan harga yang bersifat unik serta dirancang untuk menghasilkan pertukaran yang saling menguntungkan dengan pasar yang di tuju. Bauran pemasaran pada dasarnya terdiri atas empat bidang strategi pemasaran yaitu:

1. Keputusan pemasaran yang akan mengubah ide dasar dari barang atau jasa keseluruhan. Keputusan promosi yang akan mengomunikasikan informasi yang berguna pada pasar tujuan.

2. Keputusan distribusi mengenai pengiriman produk kepada konsumen.

3. Keputusan harga yang menyatakan nilaipertukaran yang dapat diterima pada barang atau jasa.

Green Marketing. Menurut Tjahja \& Hendriani dkk, (2014:199) "pemasaran hijau adalah suatu metode iklan yang mempromosikan produk dan kaitannya dengan kepekaan terhadap lingkungan kepada calon pembelian". Sedangkan Colomarde 2000 dalam Sumarwan (2012:215) "pertimbangan ekologi merupakan variabel yang relevan untuk mencapai tujuan ekonomis dari perusahaan telah menuju pada suatu konsep marketing baru, yaitu green marketing".

Menurut Rahbar \& Wahid (dalam Setiyaningrum \& Udaya dkk, 2015:315) menyatakan bahwa, eco-label, eco brand, dan iklan bertema lingkungan diidentifikasikan sebagai alat pemasaran hijau yang dapat meningkatkan pengetahuan konsumen mengenai produk ramah lingkungan. Alat pemasaran hijau diyakini menjadi sarana yang memudahkan bagi konsumen mempersepsikan produk hijau, memunculkan kesadaran akan produk hijau, dan mendorong konsumen untuk membeli produk ramah lingkungan.

Jurnal Ilmu Manajemen Advantage, Vol.01, No.1, Juni, 2017 
Irawati:Pengaruh Green Marketing dan Green Product terhadap Keputusan Pembelian...

Green Product . Menurut Ottman (dalam Sumarwan dkk, 2012:235) "isu produk hijau sangat bervariasi dan kompleks karena meliputi setiap fase dari daur hidup produk tersebut". Tjahja \& Hendriyani dkk, (2014:201) "green product dikemukakan bahwa terdapat lima keuntungan dalam berasosiasi dengan produk hijau, yaitu keuntungan efesiensi, cost effective (biaya yang efektif), kesehatan dan keamanan, performance (kinerja) dan status, dan kenyamanan".

Dalam ruang lingkup pemasaran, pengertian produk dapat dikaitkan dengan produk fisik. Menurut Setiyaningrum \& Udaya dkk, (2015:88) produk dapat dilihat dari berbagai sudut pandang diantaranya:

1. Sudut pandang yang pertama adalah produk inti (core product) produk inti adalah produk yang menjadi alasan utama dari sebuah transaksi.

2. Produk dalam pengertian yang lebih luas, artinya produk inti ditambah layanan-layananlain. Layanan untuk sebuah pupuk organik.

3. Apabila produk dilihat dari keuntungan utama yang ditawarkan, yang disebut produk generik.

Keputusan Pembelian. Menurut Kotler \& Keller (2009:268) "mendefinisikan keputusan pembelian adalah mengidentifikasikan semua pilihan yang mungkin memecahkan persoalan dan menilai pilihan-pilihan secara sistematis dan objektif serta sasaran yang menentukan keuntungan, kerugian masing-masing".

\section{Hipotesis}

Berdasarkan perumusan masalah dan tujuan dalam penelitian ini, maka hipotesis dikemukakan sebagai berikut:

a. Hipotesis Pertama

H0: Tidak terdapat pengaruh green marketing secara signifikan terhadap keputusan pembelian pupuk organik di Kios Tani Mulyo Kedungrejo Kabupaten Lumajang.

Ha: Terdapat pengaruh green marketing secara signifikan terhadap keputusan pembelian pupuk organik di Kios Tani Mulyo Kedungrejo Kabupaten Lumajang.

\section{b. Hipotesis Kedua}

H0: Tidak terdapat pengaruh green product secara signifikan terhadap keputusan pembelian pupuk organik di Kios Tani Kedungrejo Kabupaten Lumajang.

Ha: Terdapat pengaruh green product secara signifikan terhadap keputusan pembelian pupuk organik di Kios Tani Mulyo Kedungrejo Kabupaten Lumajang. 
Irawati:Pengaruh Green Marketing dan Green Product terhadap Keputusan Pembelian...

\section{c. Hipotesis Ketiga}

H0: Tidak terdapat pengaruh green marketing dan green product secara simultan signifikan terhadap pupuk organik di Kios Tani Mulyo Kedungrejo Kabupaten Lumajang.

Ha: Terdapat pengaruh green marketing dan green product secara simultan signifikan terhadap pupuk organik Kios Tani Mulyo Kedungrejo Kabupaten Lumajang.

\section{METODE PENELITIAN}

Jenis penelitian ini adalah penelitian kuantitatif dengan mencari konsumen yang bersifat assosiatif yang bersifat kausal. Lokasi yang diambil yaitu Kios Tani Mulyo Kedungrejo Kabupaten Lumajang. Populasi dalam penelitian ini yaitu konsumen Kios Tani Mulyo Kedungrejo Kabupaten Lumajang periode Januari 2017 - Maret 2017 yang berjumlah 45. Teknik pengambilan sampel yang digunakan dalam penelitian ini adalah simple random sampling. Sampel yang digunakan adalah konsumen Kios Tani Mulyo Kedungrejo Kabupaten Lumajang yang berjumlah 30 anggota sampel. Teknik pengumpulan data yang digunakan yaitu wawancara, observasi, dokumentasi, kuesioner, dan studi pustaka. Teknik analisis data yang digunakan dalam penelitian ini yaitu regresi linier berganda.

\section{HASIL DAN PEMBAHASAN}

Uji Validitas. Variabel green marketing mempunyai 3 item pernyataan dimana semua pernyataan dinyatakan valid dengan nilai $r$ hitung $>0.3$. Variabel green product mempunyai 4 item pernyataan dimana semua pernyataan dinyatakan valid dengan nilai $r$ hitung $>0.3$. Variabel keputusan pembelian mempunyai 5 pernyataan dimana semua pernyataan dari variabel keputusan pembelian dinyatakan valid dengan nilai $r$ hitung $>0.3$.

Uji Reliabilitas. Hasil uji reliabilitas dalam penelitian ini menunjukkan koefisien reliabilitas Cronbach's Alpha untuk variabel green marketing 0.529, dimana koefisisen 0.529 masuk dalam kriteria cukup reliabel. Koefisien reliabilitas Cronbach's Alpha untuk variabel green product sebesar 0.730, dimana koefisisen 0.730 masuk dalam kriteria reliabel. Koefisien reliabilitas Cronbach's Alpha untuk variabel keputusan pembelian sebesar 0.739, dimana koefisien 0.739 masuk dalam kriteria reliabel.

Jadi dapat disimpulkan bahwa kuesioner yang digunakan untuk mengukur variabel green marketing, green product dan keputusan pembelian merupakan kuesioner yang handal karena dapat memberikan hasil yang 
Irawati:Pengaruh Green Marketing dan Green Product terhadap Keputusan Pembelian... tidak berbeda jika dilakukan pengukuran kembali terhadap subjek yang sama pada waktu yang berlainan.

\section{Hasil Pengujian Asumsi Klasik}

Hasil Uji Normalitas. Hasil pengujian menunjukkan nilai mean, median, dan mode mengumpul di satu titik tengah. Hal ini berarti bahwa model regresi tersebut sudah berdistribusi normal.

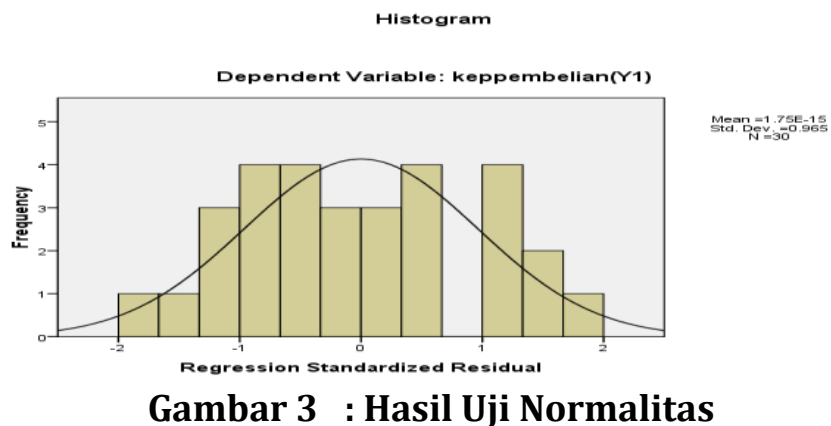

Sumber Data: Hasil Pengolahan Data Kuesioner dengan SPSS, 2017

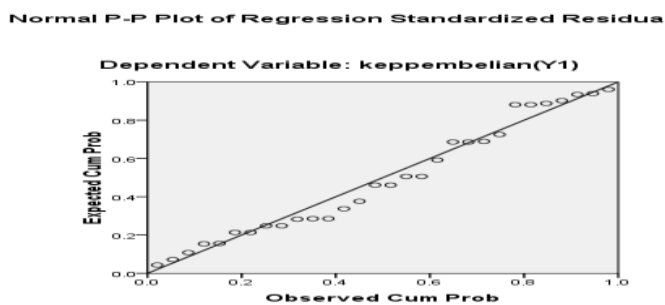

Gambar 4 : Hasil Uji Normalitas

Sumber Data: Hasil Pengolahan Data Kuesioner dengan SPSS, 2017

Hasil pengujian menunjukkan titik-titik berada tidak jauh dari garis diagonal. Hal ini berarti bahwa model regresi tersebut sudah berdistribusi normal.

Hasil Uji Multikolinieritas. Data dikatakan Bebas multikolinieritas, jika data tersebut menunjukkan nilai VIF yang cukup kecil, dimana semuanya berada di bawah 10 dan nilai tolerance lebih dari 0,1 maka hasil uji multikolinieritas disimpulkan dalam tabel sebagai berikut:

Tabel 1 Rekapitulasi Hasil Pengujian Multikolinieritas

\begin{tabular}{|l|l|l|l|}
\hline \multicolumn{1}{|c|}{ Variabel } & $\begin{array}{c}\text { Toleranc } \\
\boldsymbol{e}\end{array}$ & VIF & \multicolumn{1}{c|}{ Keterangan } \\
\hline $\begin{array}{l}\text { Green } \\
\text { marketing } \\
\left(\mathrm{X}_{1}\right)\end{array}$ & 0,949 & 1.064 & $\begin{array}{l}\text { Bebas } \\
\text { Multikolinieritas }\end{array}$ \\
\hline $\begin{array}{l}\text { Green product } \\
\left(\mathrm{X}_{2}\right)\end{array}$ & 0,940 & 1.064 & $\begin{array}{l}\text { Bebas } \\
\text { Multikolinieritas }\end{array}$ \\
\hline
\end{tabular}

Sumber Data: Hasil Pengolahan Data Kuesioner dengan SPSS, 2017 
Irawati:Pengaruh Green Marketing dan Green Product terhadap Keputusan Pembelian...

Berdasarkan tabel diatas hasil pengujian menunjukkan bahwa semua variabel yang digunakan sebagai prediktor model regresi menunjukkan nilai VIF yang cukup kecil, dimana semuanya berada di bawah 10 dan nilai tolerance lebih dari 0,1 . Hal ini berarti bahwa variabel bebas yang digunakan dalam penelitian tidak menunjukkan adanya gejala multikolinieritas, jadi semua variabel independen dalam penelitian ini adalah variabel yang saling independen, sehingga dapat dilanjutkan dalam pengujian regresi linier berganda.

\section{Hasil Uji Heteroskesdatisitas}

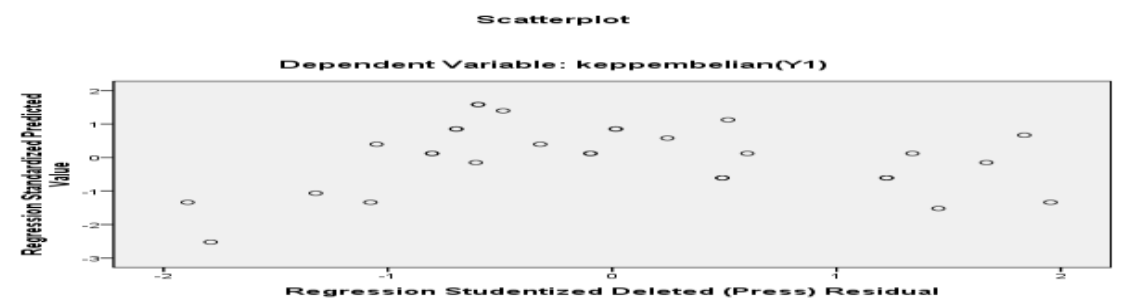

Gambar 5: Hasil Uji Heteroskesdatisitas

Sumber Data: Hasil Pengolahan Data Kuesioner dengan SPSS, 2017

Pada grafik scatter plot terlihat bahwa titik-titik menyebar secara acak serta tersebar baik di atas maupun dibawah. Hal ini dapat disimpulkan tidak terjadi heteroskedastisitas pada model regresi ini.

Fungsi Analisis Regresi Linear Berganda. Dalam penelitian ini memperoleh hasil analisis regresi linear berganda sebagai berikut:

$$
\begin{aligned}
& \mathrm{Y}=11,132-0,313 \mathrm{X}_{1}+0,837 \mathrm{X}_{2}+\mathrm{e} \\
& \text { Keterangan: } \\
& \mathrm{Y} \quad=\text { Keputusan pembelian } \\
& 11,132=\text { Konstanta } \\
& -0,313=\text { Koefisien green marketing } \\
& 0,837=\text { Koefisien green product } \\
& \mathrm{X}_{1} \quad=\text { Green marketing } \\
& \mathrm{X}_{2} \quad=\text { Green product } \\
& \mathrm{e} \quad=\text { error }
\end{aligned}
$$

\section{Hasil Pengujian Hipotesis}

Hasil Uji t (Uji Parsial). Hasil uji t pada variabel $\mathrm{X}_{1}$ yaitu green product diperoleh nilai $t_{\text {hitung }}=-0,892$ dengan signifikansi 0,380. Dengan menggunakan batas signifikansi $5 \%$ atau 0,05 diperoleh $t_{\text {tabel }}$ sebesar $\pm 2,048$. Ini berarti thitung $(-0,892)<t_{\text {tabel }}(2,048)$, yang berarti $\mathrm{H}_{0}$ diterima dan $\mathrm{Ha}$ 
Irawati:Pengaruh Green Marketing dan Green Product terhadap Keputusan Pembelian...

ditolak. Dengan tingkat signifikansi 0,005 yang berada di atas signifikansi 0,05 maka dapat disimpulkan bahwa tidak terdapat pengaruh green marketing yang signifikan secara parsial terhadap keputusan pembelian.

Hasil uji $\mathrm{t}$ pada variabel $\mathrm{X}_{2}$ yaitu yaitu green product diperoleh nilai $\mathrm{t}$ hitung $=4,297$ dengan signifikansi 0,000. Dengan menggunakan batas signifikansi $5 \%$ atau 0,05 diperoleh tabel sebesar $\pm 2,048$. Ini berarti $t_{\text {hitung }}$ $(4,297)>t_{\text {tabel }}(2,048)$, yang berarti $\mathrm{H}_{0}$ ditolak dan Ha diterima. Dengan tingkat signifikansi 0,000 yang berada dibawah batas signifikansi 0,05 maka dapat disimpulkan bahwa terdapat pengaruh green product yang signifikan secara parsial terhadap keputusan pembelian.

Hasil Uji F (Uji Simultan). Hasil uji F pada variabel penelitian diperoleh nilai $F$ hitung $=9,246$ dengan tingkat signifikansi 0,003. Dengan menggunakan batas signifikansi $5 \%$ atau 0,05 , diperoleh $\mathrm{F}$ tabel sebesar 3,35. Ini berarti $\mathrm{F}_{\text {hitung }}>\mathrm{F}_{\text {tabel, }}$ yang berarti $\mathrm{H}_{0}$ ditolak dan Ha diterima. Dengan tingkat signifikansi 0,007 yang berada di bawah batas signifikansi 0,05 maka dapat disimpulkan bahwa terdapat pengaruh green marketing dan green product yang signifikan secara simultan terhadap keputusan pembelian pupuk organik di Kios Tani Mulyo Kedungrejo Kabupaten Lumajang.

Koefisien Determinasi. Dari hasil perhitungan dengan menggunakan program SPSS versi 16 dapat diketahui bahwa koefisien determinasi $(R$ square) yang diperoleh sebesar 0,406. Hal ini berarti 40,6\% keputusan pembelian pupuk organik diKios Tani Mulyo Kedungrejo Kabupaten Lumajang dapat dijelaskan oleh variabel green marketing dan green product sedangkan sisanya 59,4\% keputusan pembelian pupuk organic di Kios Tani Mulyo Kedungrejo Kabupaten Lumajang dipengaruhi oleh variabel-variabel lainnya yang tidak diteliti dalam penelitian ini seperti green consumerism (konsumen hijau), harga serta sikap konsumen.

\section{Pembahasan Pengaruh Green Marketing Terhadap Keputusan}

Pembelian. Berdasarkan hasil pengujian hipotesis pertama yang menyatakan bahwa tidak terdapat pengaruh green marketing secara parsial signifikan terhadap keputusan pembelian pupuk organik di Kios Tani Mulyo Kedungrejo Kabupaten Lumajang. Green marketing tidak berpengaruh terhadap keputusan pembelian dikarenakan pupuk organik itu sekarang menjadi kebutuhan wajib untuk sistem pertanian, oleh karena itu, meskipun Kios Tani Mulyo Kedungrejo Kabupaten Lumajang tidak menerapkan kegiatan seperti yang dijelaskan di atas petani tetap membeli pupuk organik tersebut. Penyuluhan tentang tata cara penggunaan pupuk yang diberikan oleh Kios Tani Mulyo Kedungrejo Kabupaten Lumajang hampir tidak 
Irawati:Pengaruh Green Marketing dan Green Product terhadap Keputusan Pembelian...

diperhatikan karena tata cara penggunaan pupuk sudah tertera pada brosur yang disebarkan, sehingga petani menganggap penyuluhan yang dilakukan tidak penting bagi petani.

Pembahasan Pengaruh Green Product Terhadap Keputusan Pembelian. Hasil pembahasan ini berkaitan dengan pengujian hipotesis kedua menunjukkan bahwa green product terdapat pengaruh yang signifikan terhadap keputusan pembelian pupuk organik di Kios Tani MulyoKedungrejo Kabupaten Lumajang. Dari hasil penelitian menunjukkan bahwa sebagian besar konsumen yang pernah membeli pupuk organik di Kios Tani Mulyo Kedungrejo Kabupaten Lumajang memberikan tanggapan setuju terhadap variabel green product. Karena green product sangat berpengaruh terhadap keputusan pembelian, sesuai dengan kenyataannya bahwa sebagian besar konsumen lebih memilih produk yang ramah lingkungan dan tidak membahayakan manusia. Konsumen memilih untuk pola hidup sehat dengan menggunakan produk organik yang ramah lingkungan.

Pembahasan Pengaruh Green Marketing dan Green Product Terhadap Keputusan pembelian. Hasil pengujian hipotesis menunjukkan bahwa green marketing dan green produk secara simultan berpengaruh siginifikan terhadap keputusan pembelian pupuk organik di Kios Tani Mulyo Kedungrejo Kabupaten Lumajang. Meskipun variabel green marketing tidak berpengaruh secara parsial signifikan tetapi ketika digabungkan dengan variabel green product maka dapa tberpengaruh signifikan terhadap variabel keputusan pembelian. Kegiatan green marketing dan green product yang berjalan searah atau berdampingan dapat mempengaruhi petani untuk membeli pupuk organik di Kios Tani Mulyo Kedungrejo Kabupaten Lumajang. Hal ini berarti kedua variabel yaitu green marketing dan green product dapat meningkatkan keputusan pembelian pupuk di Kios Tani Mulyo Kedungrejo Kabupaten Lumajang. Petani memutuskan membeli pupuk organik di Kios Tani Mulyo Kedungrejo Kabupaten Lumajang karena memahami manfaat adanya green marketing dan green product .

\section{PENUTUP}

Simpulan. Penelitian ini bertujuan untuk mengetahui pengaruh green marketing dan green product terhadap keputusan pembelian pupuk organik di Kios Tani Mulyo Kedungrejo Kabupaten Lumajang baik secara parsial maupun simultan dengan menggunakan teknik analisis regresi linier berganda. Mulai dari perumusan masalah, tujuan masalah dan hipotesis penelitian serta pembahasan hasil penelitian yang telah dikemukakan pada 
Irawati:Pengaruh Green Marketing dan Green Product terhadap Keputusan Pembelian...

bab sebelumnya dapat ditarik beberapa kesimpulan dari penelitian sebagai berikut:

a. Hasil pengujian hipotesis pertama menunjukkan tidak terdapat pengaruh variabel green marketing terhadap keputusan pembelian pupuk organik.

b. Hasil pengujian hipotesis kedua menunjukkan terdapat pengaruh variabel green product terhadap keputusan pembelian pupuk organik.

c. Hasil pengujian hipotesis menunjukkan adanya pengaruh variabel green marketing dan variabel green product secara simultan terhadap keputusan pembelian pupuk organik. Dengan koefisien determinasi menunjukkan bahwa sebesar 40,6\% keputusan pembelian dapat dijelaskan oleh variabel independen yaitu green marketing dan green product, sedangkan sisanya 59,4\% keputusan pembelian dipengaruhi oleh variabel-variabel lainnya yang tidak diteliti dalam penelitian ini seperti green consumerism (konsumen hijau), harga serta sikap konsumen.

Saran. Berdasarkan kesimpulan yang diperoleh dalam penelitian ini, maka diajukan saran-saran sebagai pelengkap terhadap hasil penelitian yang dapat dierikan sebagai berikut:

a. Bagi Peneliti

Diharapkan peneliti dapat mengadakan penelitian yang lebih mendalam tentang green marketing dan green product dan pengaruhnya terhadap keputusan pembelian

b. Bagi Sekolah Tinggi Ilmu Ekonomi Widya Gama Lumajang

Lebih mengembangkan penelitian-penelitian yang belum pernah diteliti para mahasiswa sehingga dapaat meningkatkan mutu STIE Widya Gama Lumajang.

c. Bagi Perusahaan

Kegiatan green marketing disarankan untuk meningkatkan penjualan dan lebih kratif lagi dalam pemasaran produk sehingga konsumen tertarik untuk membeli pupuk organik, untuk kegiatan green product harus dipertahankan keunggulannya dan lebih baiknya ditingkatkan, untuk kegiatan berinovasi yang lebih handal, yang ramah lingkungan akan kebutuhan pelanggannya.

d. Bagi Peneliti Selanjutnya

Diharapkan bagi peneliti selanjutnya lebih memperluas dan mengembangkan penelitian yang telah dilakukan, peneliti lain dapat melengkapi dengan variabel independen dan dependen lain yang belum 
Irawati:Pengaruh Green Marketing dan Green Product terhadap Keputusan Pembelian...

diangkat oleh peneliti dahulu misalnya green consumerism (konsumen hijau), harga serta sikap konsumen, agar hasil tersebut mempunyai perkembangan yang semakin serupa.

\section{DAFTAR RUJUKAN}

Hadisuwito, Sukamto. 2013. Membuat Pupuk Organik Cair. PT Agro Media Pustaka Jakarta.

Hasibuan, Malayu. 2015. Manajemen: Dasar, Pengertian, dan Masalah. PT Bumi Aksara. Jakarta.

Kotler, Pillip dan Kevin Line Keller. 2009. Manajemen Pemasaran. Edisi Tiga Belas. Jilid Satu. Erlangga: Jakarta.

Mamang dan Sopiah. 2013. Perilaku Konsumen Pendekatan Praktis Disertai Himpunan Jurnal Penelitian. Andi: Yogyakarta.

Rangkuti, Freddy. 2009. Strategi Promosi yang Kreatif dan Analisis Kasus Integrated Marketing Communication. PT Gramedia Pustaka Utama: Jakarta

Setiyaningrum dan Udaya, dkk. 2015. Prinsip-Prinsip Pemasaran. Andi: Yogyakarta. 